\title{
Development of ICMLS Version 2 (Integrated Communication and Mobile Laboratory Simulator) To Improve 4.0 Century Industry Skills in Vocational Schools
}

https://doi.org/10.3991/ijim.v14i08.12625

Deni Darmawan

Universitas Pendidikan Bandung, Bandung, Indonesia

deni_darmawan@upi.edu

\begin{abstract}
The focus of this research was to develop an "ICMLS (Integrated Communication Mobile Laboratory Simulator)" in the form of mobile laboratories innovations for vocational teachers and students of Computer and Network Engineering. This was produced through the development of R \& D with support from industrial partners in order to make all teachers and students in Vocational High School, West Java experiences the quality of the product. The prototype developed accommodated all practical activities for class $\mathrm{X}$ to XII in one integrated package for server and client functions. This research was conducted for 2 years, and in the first year, 2018, ICMLS version 1.0 was produced and 2.0 will be produced in the second year. This product can improve the competence of Vocational students in Computer and Network Engineering Study Programs to compete in the 4.0 Industrial Revolution Era which is more characterized by Artificial Intelligence and Big Data. This was evident from the increase in the average competency test of students from 85.13 to 85.53 produced from the lowest initial skill average of 77.9 to the highest of 89.4
\end{abstract}

Keywords-ICMLS, Mobile Laboratory, Vocational High School, Computer Network Engineering.

\section{$1 \quad$ Introduction}

There is intense competition in the labor market through the world, especially for local, national, and international employees, furthermore, Indonesia and other developing countries also face this challenge [1]. However, it has been discovered that one of the best ways of producing prospective workers is education. Since the period of the Dual System Education curriculum in the 80s, formal education has been contributing greatly to the integration of the skills and knowledge needed by industries into the programs of vocational school education. Moreover, despite the technological advancement of this era, this system is expected to maintain its role in preparing students for the labor market. However, there are differently effective, 
inexpensive and innovative learning models that can be equally implemented to make this happen. One of these is the rapid development of laboratory requirements through different technologies. This is supported by the findings of [2] that the high-speed development of technologies and its consequent effect on education has greatly influenced both traditional teaching and learning mode. However, there is a high financial implication in developing laboratory with a number of software and hardware tools, especially in the areas of Information and Communication Technology such as Computer Engineering and Networking, Multimedia, and others. In Indonesia, there are many SMKs with limited facilities and infrastructure such as special laboratories for practicum. This shows that vocational learning still lacks basic amenities needed for adequate knowledge impartation, therefore, several efforts have been made by researchers, practitioners, industries, and schools towards the establishment of the innovative, cheap and reliable modern laboratory.

Integrated Communication Mobile Laboratory Simulator (ICMLS) is a mobile laboratory developed for practical activities of vocational students in Computer and Network Engineering. It can be applied in many activities such as:

1. Assembling personal computers.

2. Installing a basic operating system.

3. Applying safety, occupational health and the environment (K3LH).

4. Implementing peripheral functions and PC installation.

5. Diagnosing problems with PC operation and peripherals.

6. Repairing and/or resetting PC Systems.

7. Conducting PC maintenance.

8. Installing GUI operating system and CLI.

9. Installing software.

10. Installing local network devices (LAN).

11. Diagnosing problems with operation of PCs connected to the network.

12. Repairing and/or re-setting network connections.

13. Installing GUI and text-based network operating systems.

14. Installing broad-based network devices (WAN).

15. Making the design of network security system.

16. Repairing and/or re-setting broad-based network (WAN) connections.

17. Administration of servers in the network.

18. Designing and analyzing WANs.

19. Designing a web database for server content [3].

There are various challenges observed in the development of 19 laboratories needed in teaching the courses highlighted above through ICMLS version 1.0. Therefore, version 2.0 was produced to be an innovative model of laboratory automation systems with some peripheral functions aimed at achieving effective and efficient learning experience. It was created using mechanical technology, an electronic microcontroller such as the automatic motion monitor screen system, mini BTS automatic motion system, keyboard, remote control, and server computer operating systems. 
Therefore, the purpose of this study was to provide innovative, modern, userfriendly, mobile, practical and inexpensive laboratories in order to effectively prepare vocational graduates of Computer and Network Engineering Study Programs in Indonesia for facing the 4.0. era [4]. Based on these objectives, this research specifically produced a number of concrete solutions that can be immediately applied in schools and they include: 1) Mobile laboratory prototype model. 2) Design and development of prototype Mobile Laboratory which is able to maximally integrate infrastructures owned by Vocational Schools. 3) An affordable ICMLS manufacturing model of Mobile Laboratory to meet the needs of these schools 4) Forms of ICMLS implementation to facilitate practicum and competency test in all Referral Vocational Schools in each Province.

The ICMLS model found a number of ideas from Educational Technology experts that can be used in learning practical simulation media in computer science and engineering. Likewise, it was practically tested for efficiency in conducting competency tests and speed for students in mastering all components of client and server computers. Its design and architecture also utilize transparent materials and open spaces with consideration for occupational health and safety. From the HumanComputer Interaction perspective, the program has the ability to diagnose a student's weaknesses while studying computer and network techniques. The ICMLS integrated hardware, software, and environ ware functions through the automatic and quick control of user's brainwave, in this case for teacher and students. Therefore, through the implementation of the findings of this program, students, teachers, schools, education technology experts, computer science and engineering professionals, and the informatics industry can be made to understand information technology. Practically, it allows the computer industry to have a clear idea of the product to be produced with respect to users' need.

\section{$2 \quad$ Literature Review}

\subsection{Mobile laboratory}

This term is defined from several previous research findings where it was termed 'Mobile Technology' to be an object with a moving technological character. It is lightweight, moveable and can be used for the benefit of learning anytime and anywhere without having to be in a physical laboratory [5] and also applied for competency test of students. Whereas [6] asserted that the mobile laboratory is "a place for conducting experiments, investigations, etc. related to physics, chemistry, biology or other fields of science".

Based on the above understanding, the mobile laboratory can be interpreted as a set of tools that can be used anywhere because of its movable nature to conduct research or experiments. In this research, it was constructed from the combination of software, hardware, ergonomic systems, architecture, multimedia, mechanic automatics, artificial intelligence, and remote control. This technology has an animated software response for use in learning supported by animated pedagogical agents (APA) as 
stated by [7]. It was particularly designed for the learning process and vocational competency test of computer and network engineering study programs. This is in accordance with the opinion of [8] that the evaluation configuration module must provide an effective user interface in assessing the competency of clients.

The development of the mobile laboratory was founded on the assumption that innovative learning requires the preparation of modern education media. In support of this, [9] emphasized that media education should lead to positive, critical and differentiated attitudes in making active choices and offer knowledge in three areas including: 1) Communication or communication-mediating means 2) Reception and 3) Content analysis.

\subsection{Computer and network engineering}

The study of computer and network engineering in high and vocational schools or equivalent level is part of the competency needing in studying information and communication technology [10]. It includes algorithms and computer programming, computer and network assembly, as well as software operation. It also requires an understanding of electrical engineering and computer science in order to develop and integrate software and hardware. In communication science, the study of computer networks is closely related to Computer-Mediated Communication (CMC). [11] explained that the same technology is afforded at different levels of visibility and influenced by behaviors relating to availability to colleagues, engagement in communication, and forms of knowledge sharing.

\subsection{Computer and network devices}

Recently, computer technology has experienced very rapid development in various fields. Its influence is frequently seen in every working system innovation and automation that has been developed to support human work. The education sector requires the application of this technology; however, a number of researches have been conducted to ensure students, teachers and other stakeholders in the sector enjoy the benefit of technological advancements.

Through the study of different architectures, networking and the combination of automation, both software, and hardware, a new product was produced to reduce the costs of procurement and maintenance of effective learning. The results of this innovation produced an Electronic Simulator which can help students to learn computer network science. Furthermore, it can be said to be an example of [9]'s Computer-Mediated Communication used in supporting practical learning activities without worrying about obstacles faced by users, especially the availability of laboratory space. Therefore, it can be established that modern computer, communication, multimedia, and network technologies are aimed at improving human communication and the amount of information currently processed by the new media is far from the traditional media [10].

It is expected that the 'ICMLS Model' would be developed by integrating a number of hardware devices into one multifunctional tool, ranging from learning 
communication media, basic training courses to networking analysis competency tests. Therefore, the model developed in this research consists of several computer components and networks which are integrated into one mobile laboratory package and named 'ICMLS'. However, it is important to note the basic components of personal computers, and they include:

a) Processor, the brain of a computer, and a conceptual processor consisting of Arithmetic Logical Unit (ALU), Control Unit (CU) and Memory Unit (MU).

b) Motherboard/Mainboard, the main part of a computer.

c) Memory/RAM (Random Access Memory).

d) Hard Disk, functions as a place to store data.

e) Optic Drive (Optical Disk Drive) such as CD-ROM Drive, CD Writer, Combo Drive, DVD-ROM Drive and DVD Writer.

f) Keyboard.

g) Mouse.

h) Expansion Card (VGA Card, Sound Card, LAN Card) used in expanding the PC's capabilities;

i) Modem, which means Modulator and Demodulator.

j) Monitor, a device to display output from a computer in form of an image (visual).

k) The printer, a peripheral device used for issuing output through prints on paper.

1) A scanner, a tool used in scanning images from a paper.

$\mathrm{m})$ External storage media, functions like a hard disk, except that it is not fixed;

n) Casing and Power Supply (PSU), which are two important components in assembling a PC.

\subsection{Industrial revolution version 4.0}

The ability of humans to think and learn as observed in the 21 st-century will soon be renewed through the introduction of various disruptive innovations [12]. This will help in creating new markets by disrupting or destroying the existing ones through the replacement of old technologies with the latest. It also helps in developing products or services in an unpredictable manner [9]. This theory was popularized in the globalization era after innovators experienced several dilemmas in producing good products. However, several researchers in education has developed different innovations different from previous ones by combining disruptive innovations with scientific products of Educational Technology [13]. ICMLS is a prototype of the products from these efforts and it was conceptually designed to integrate learning resource requirements with some subjects needed by vocational students, especially in the Department of Computer and Network Engineering. Therefore, this prototype is expected to be a response to the submission of [15] about using disruptive innovation to improve schools as reported in [14].

This study shows that a number of educational development products in the Industrial Revolution 4.0 era are produced from a combination of $21^{\text {st }}$ century competencies and individual human abilities through Hinger Order Thinking Skills 
such as: 1) Digital Economy, 2) Big Data, 3) Artificial Intelligence, Robotics (Ministry of Research Technology and Higher Education, Indonesia, 2018).

The application of these competencies in equipping vocational students is observed in the innovative product of this research.

The practicality of ICMLS is established on its ability to either get learning materials from the teacher or in the class. In this case, it involves the migration of laboratory space functions into mobile devices through the use of previous research efforts on virtual classroom [1], networking mobile games [16], education mobile world class [17], and the concept of mobile-based learning.

In order to make the ICMLS model broader through the addition of different types of subjects, several previous concepts and findings from world experts were consulted. Therefore, the design and implementation of this model with the support of government and industries would make it become one of the best ways of solving the problems of competency in all computer and network engineering study programs of all vocational schools in Indonesia. It will also make the graduates of these schools possess the capability to compete with others from Southeast Asia and other parts of the world.

\section{$3 \quad$ Research Method}

The research was conducted for over two years and divided into two periods with the first in 2018 and second, 2019. The University of Education in Indonesia, Bordeaux University, IPI, and Nusantara Vocational High School Laboratories were used for the research with support from the Republic of Indonesia Ministry of Education and Culture. Research and Development method as proposed by [18] was used. This involved ten steps and they include

1. Research and information collection

2. Planning

3. Preliminary product development

4. Preliminary field testing

5. Main product revision

6. Main field testing

7. Operational product revision

8. Operational field testing

9. Final product revision

10. Dissemination and implementation.

During the test revision phase, 8 Vocational Schools in the East Priangan region of West Java Indonesia were purposively sampled. After the production of a proven ICMLS prototype, there was a collaboration with "PT. INTI" to produce commercially. 


\section{$4 \quad$ Result and Discussion}

4.1 Mobile laboratory prototype and the requirements of computer and network engineering study programs vocational practice

The results from field studies showed that obtaining laboratory requirements for students in the Computer and Network Engineering Study Program of SMK is quite complex. The 8 Vocational Schools assessed were SMK Negeri 4 Tasikmalaya; MJPS 1 Tasikmalaya Vocational School; SMK Negeri 1 Kedawung Cirebon; SMK Negeri 1 Lemahabang Cirebon; Majalengka YPIB Vocational School; Muhammadiyah Majalengka Vocational School; SMK Negeri 3 Kuningan and SMK Negeri 1 Soreang. They reported that the model to be developed must be able to work digitally, electronically, and online in order to bridge the interaction process between server and client as emphasized by [19] in their research entitled "Online discussion compensates for suboptimal timing of supportive information presented in a digitally supported learning environment".

The prototype designed was aimed at improving the ability of the students to learn more interactively in changing conditions and places. This is in agreement with the results from [20] that mobile technologies could be used to improve performance. The model became a medium of communication between teachers and students, as well as the computer system itself. The teachers may use it to communicate with the server computer systems and students with the client computer systems or partners. These are meant to improve the learning process through the laboratory practicum. Furthermore, [21] revealed that the model is a useful way of communicating and learning. This finding is established on three major elements of communication which are senders, receivers and the media. Therefore, the model was designed in such a way that it met the requirements of the intended users and this was found to be in line with the opinions of [22] in Blended learning - State of the Nation. Figure 1 shows that illustration of the ICMLS products produced during the research process.

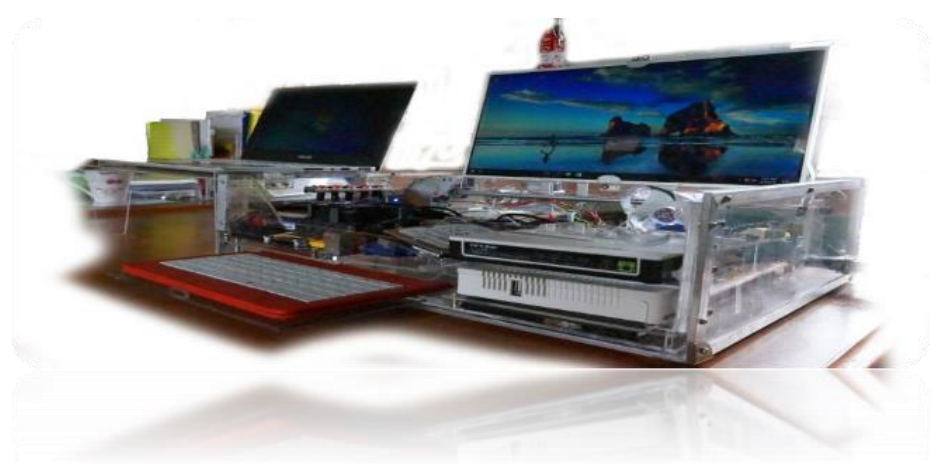

Fig. 1. Initial Portable ICMLS Model Prototype 
The initial prototype had many challenges such as mobility and lack of automatic character. Furthermore, the next phase was designed, revised and developed to be cheap, easy, mobile and have a mini tower that integrates both software and hardware in order to meet up with the requirements of a laboratory. Figure 2 shows the sketch version of ICMLS 1.0 developed during the research.

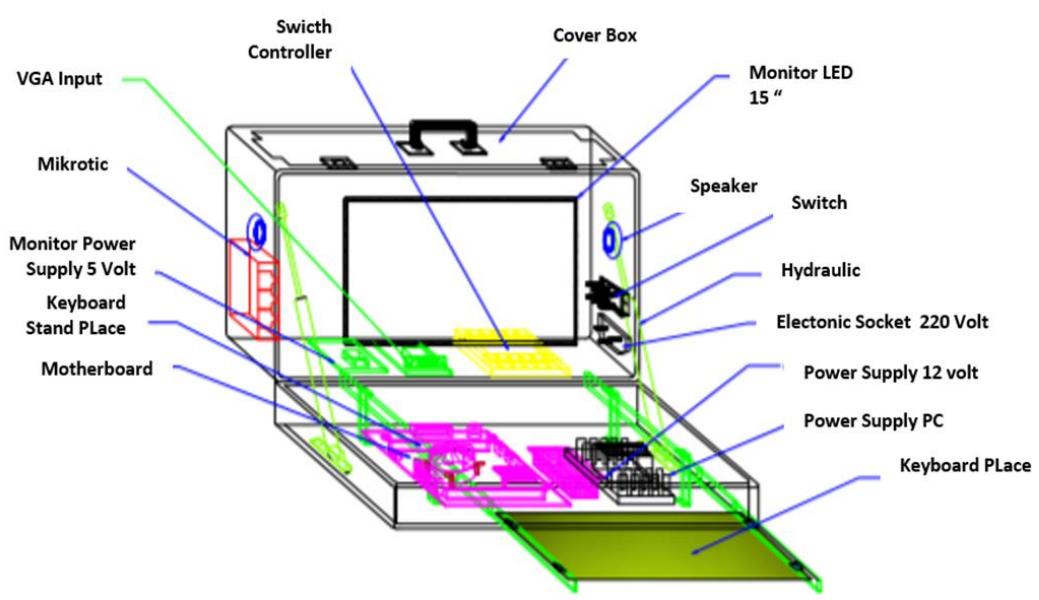

Fig. 2. Sketch of ICMLS version 1.0 prototype for Server

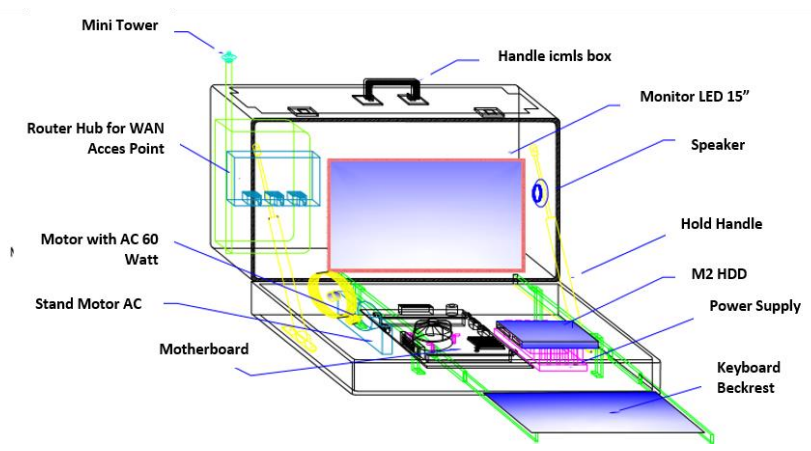

Fig. 3. Sketch of ICMLS version 1.0 prototype for Client

\subsection{Design of mobile laboratories prototype with the ability to optimally integrate the Vocational Schools infrastructure}

The results of a field study conducted on 10 Vocational Schools in West Java region revealed that there is a need for appropriate hardware and software for the model to be effectively implemented by student users [23]. It was also reported that the schools' infrastructures may also serve as an obstacle to several practical activities. However, the learning resources made available by ICMLS mobile laboratories have embodied the idea of [24] about the introduction of open 
educational resources (OER) in acquiring knowledge. Therefore, the initial hypothetical design was produced based on the results of previous researches [21].

The product was developed through the following steps

1. Preparation and measurement of all components needed for both the client and server.

2. Design of component design.

3. Design and construction of an automated system using a remote system.

4. Provision of mobile box design suitable for construction design.

5. Assembly of components and remote systems according to their functions;

6. Checking the communication automatically between the client checkbox and the server.

7. Analysis of box's ergonomic suitability during communication.

8. Analysis of communication stability between client and server boxes while communicating.

9. Communication trials between the two when simulating Computer and Network Engineering Study Programs materials.

10. Review and improvement of components compatibility, ergonomic, and speed of automation system between clients and servers.

11. Hardware box stability test when opened for a number of clients and server systems.

12. Analysis of shocks and movements that disturb stability between components in the ICMLS box server and client.

The users of this product, both teachers and students, focus on their existence through the application of the concept of Human Communication Interaction [9]. It also gives them the opportunity of communicating various learning activities in depth. The general steps involved in assembling ICMLS are as shown in Figure 4. 


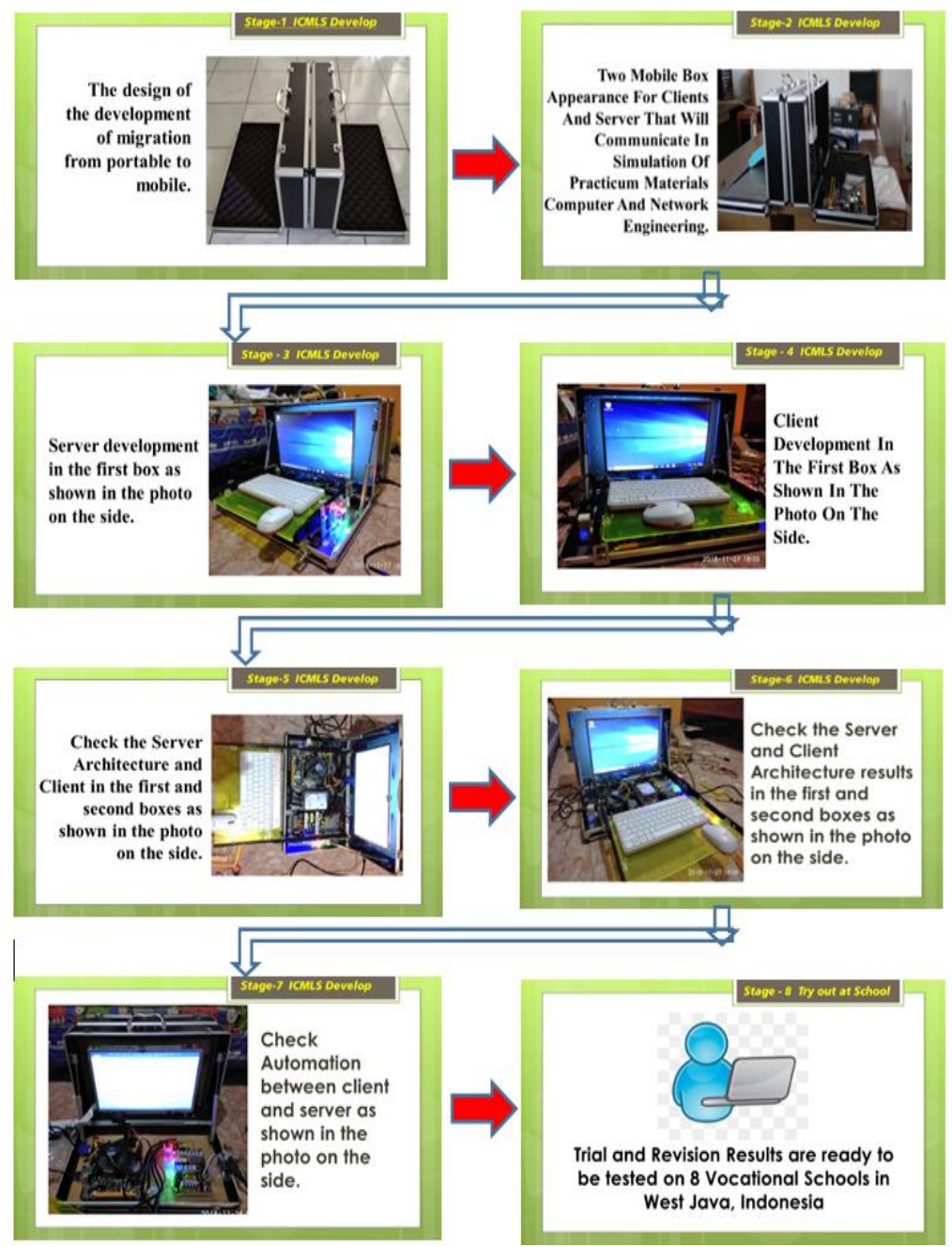

Fig. 4. ICMLS Development Stages

The ICMLS was made ready for use after the hardware and software have been adequately developed. It was tested by using it to practice a number of subject matter and competency test in the Computer and Network Engineering Study Programs department of 8 selected vocational schools. The ICMLS server and Client prototypes are presented in Figure 5. 
Paper-Development of ICMLS Version 2 (Integrated Communication and Mobile Laboratory) ...

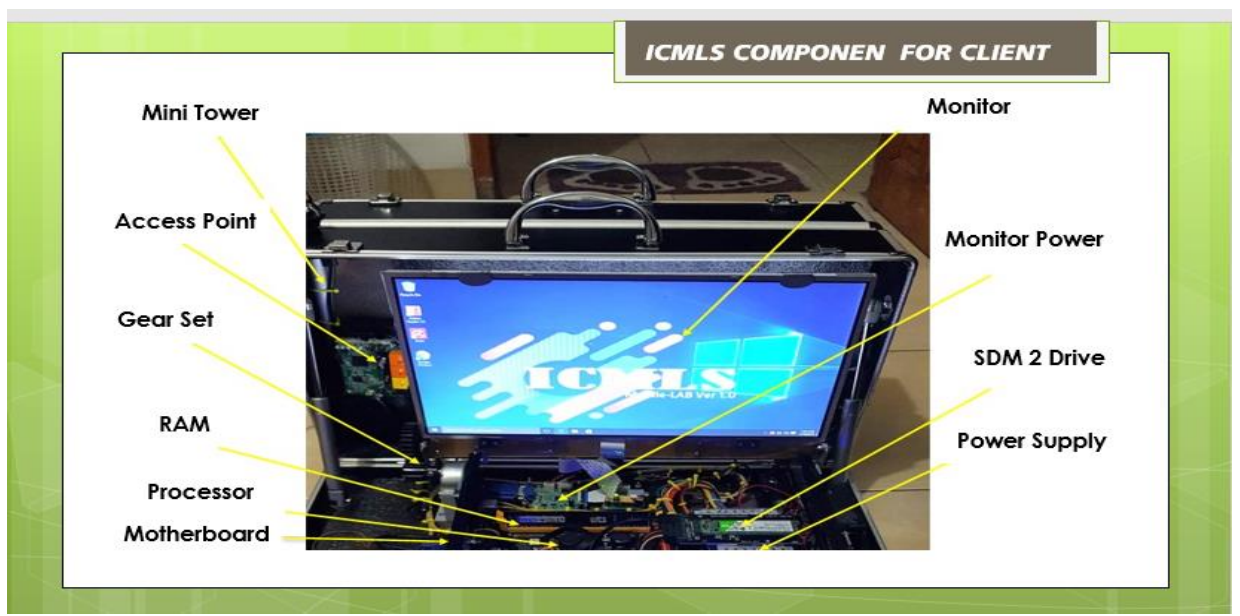

Fig. 5. Architecture of ICMLS for Client.

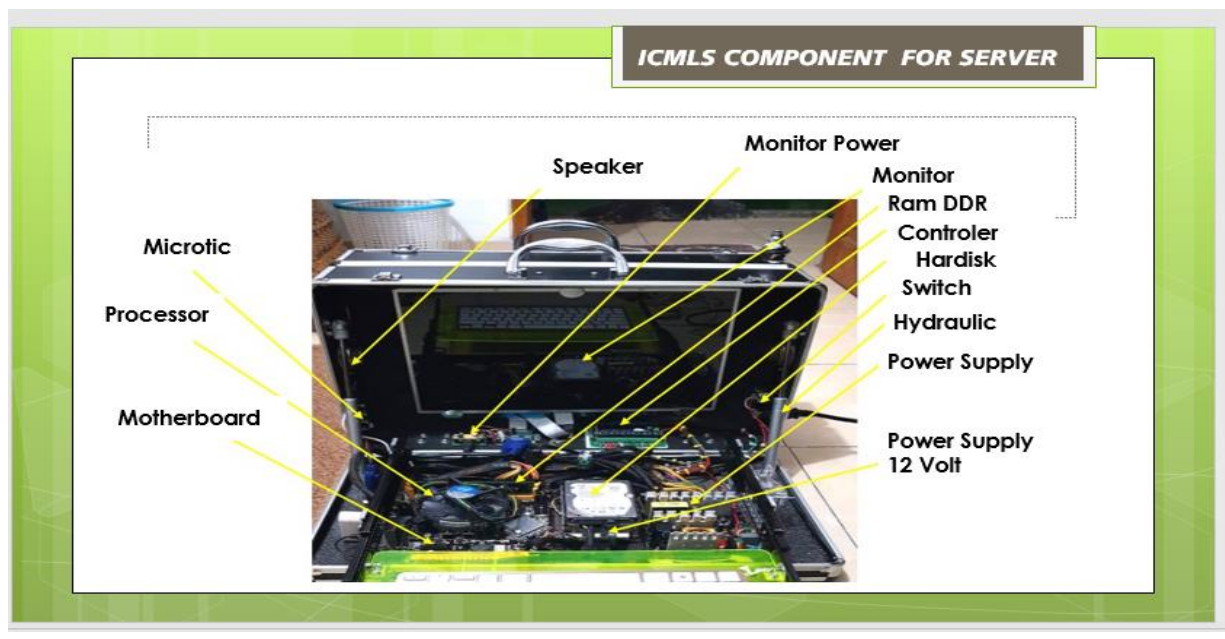

Fig. 6. Architecture of ICMLS for Server

The result of the tests conducted is shown in Figure 7. 


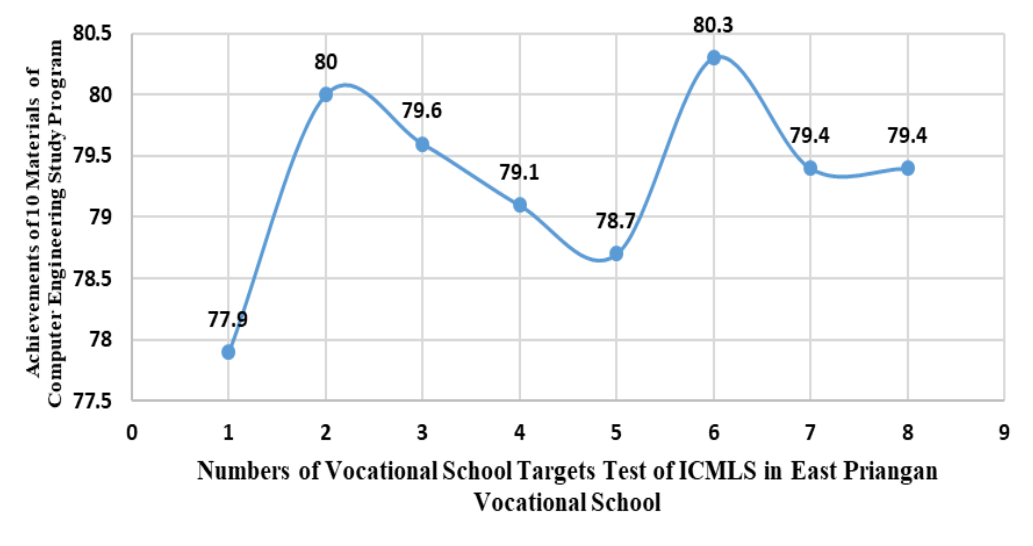

Fig. 7. Condition of Achievement Value 8 Vocational School of Computer Engineering Study Program

Table 1. List of Computer and Network Engineering Study Programs Practical Materials by Using ICMLS

\begin{tabular}{|c|l|}
\hline NO & Computer and Network Engineering Study Programs of Vocational Schools in Indonesia \\
\hline 1 & Assembling a Personal Computer \\
\hline 2 & Installing the Basic Operating System \\
\hline 3 & Applying Safety, Occupational Health and the Environment (K3LH) \\
\hline 4 & Implement peripheral functions and PC installation \\
\hline 5 & Diagnosing problems with PC operation and peripherals \\
\hline 6 & Repair and/or reset PC System \\
\hline 7 & Performing PC Maintenance \\
\hline 8 & Installing the GUI Operating System and CLI \\
\hline 9 & Installing Software \\
\hline 10 & Installing a Local Network Device (LAN) \\
\hline
\end{tabular}

The results obtained from field testing were continuously improved to rectify the weaknesses observed before the products would be commercially produced [25]. It is important to state that one of the industries that are interested in producing the product is PT. INTI in Bandung West Java, Indonesia.

\subsection{Designing ICMLS manufacturing process as a mobile laboratory for commercial production}

In order to produce ICMLS commercially, the research team partnered with the Product Production and Commercialization Sector of PT. INTI to design a flowchart as shown in Figure.7. Therefore, the target is to produce ICMLS generation 2.0 model, which is more complete with respect to architecture, automation, mobility, as well as voice conditions by 2019-2020 to facilitate its users. 


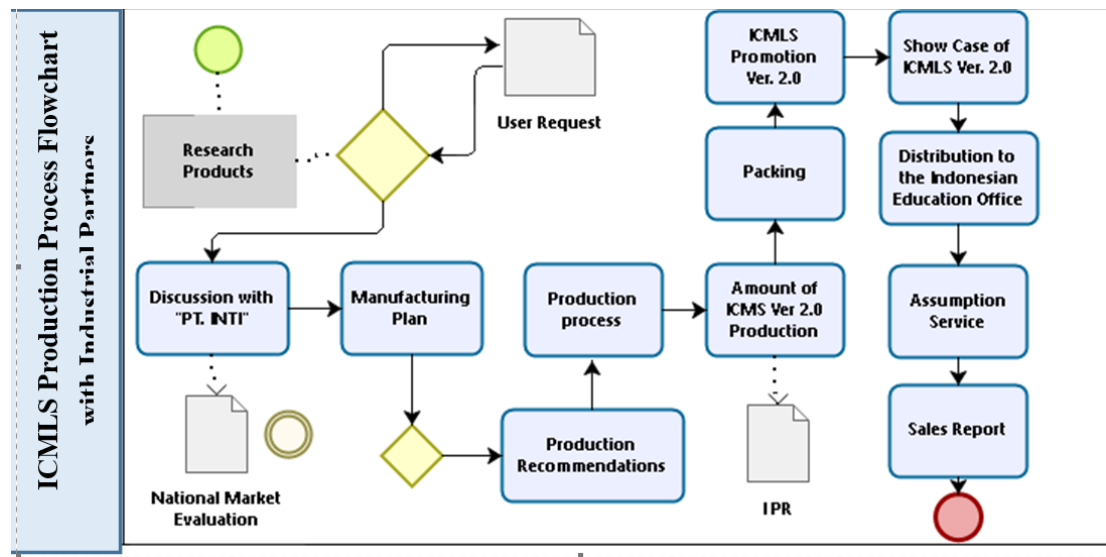

Fig. 8. ICMLS National Version Affordable Flow Manufacturing Version 2.0 by the Research Team with PT. INTI

The process shows that advancement will meet the needs of quality and inexpensive laboratories. Furthermore, ICMLS can also improve the quality of learning in Computer and Network Engineering Study Programs of Vocational Schools in developing countries throughout the world

\subsection{Implementing ICMLS to facilitate vocational school students' competencies}

The program was implemented through coordination with the head of the Computer and Network Engineering Study Programs and the homeroom teacher in charge of students' practical. Furthermore, the teacher communicated with the head of the laboratory about the use of ICMLS for students according to the practice schedule. This was conducted in groups after the students have learned the manuals, characteristics and work systems of ICMLS. Moreover, the application of Computerassisted instruction (CAI) is a relatively new practice in most African countries, where only the minority of population only access information and communication technology (ICT) [26]. This made it possible to integrate the manual materials into the ICMLS software in order to encourage interactive communication and learning. Students can make use of the materials to understand simulations involved with the use of the product.

The product was designed to be user-friendly in creating interactive communication for the teachers controlling the servers as well as the students who serve as the clients. ICMLS was equipped with voice condition as a response to the explanations of [7]. The product also makes it possible to simulate and demonstrate all education courses in the Computer and Network Engineering Study Programs for learning purposes. However, there is a need to manage the quantitative access rights of users by modifying the IP address of ICMLS version 1.0 products from 192. 168. 
1.1 for Access Points and 192.168.88 for Microtics. The Wi-Fi access address is: 1) Icmls_client. 2) Icmls mobile laboratory as explained by [6].

These can communicate in a limited manner through mini towers or antennas installed on the server section while the development of automatic movement instead of open-closed client screen was controlled by the level of remote-control system developed based on research conducted by [6]

Several technologies are implemented in the design and production phase such that: Access control system used VVS technology through control remoter. 2)

Mechanical technology used mini hydraulics on the opening part of the Client and server. 3) The open layer client technology made use of an electromagnetic wave amplifier system to trigger the mechanical technology of the client screen. This was supported by the power generated from the Dynamo AC Motor that was sending power to the gearshift. 4) Conventional technology for wheels. 5) Engineering design for the ICMLS Box. While standard network application system, windows installation, office, MS Access, and other applications made up the software technology used in developing ICMLS version 1.0.

The implementation of the product equipped with a manual guide for the targeted teachers and students was analyzed. It was discovered that the inclusion of the manual can result in effective and efficient use of the ICMLS product. Other aspects of OSH such as the required power voltage, safe placement of the products, and level of accuracy for convenience are expected to be adhered to by the users

During the practicum, the ICMLS was placed in front of the class for students to pay attention to the communication process between the client and the server. However, [27] advocated building on the competencies that students bring to the learning situation. In accordance with this, ICMLS was designed to support students' efforts in achieving their competence. Furthermore, in learning subjects such as computer design and installation, students were allowed to move towards the product and make use of it in turn. The ICMLS can also be placed in the middle of the classroom where all students surround it and observe how it is being used by their teachers and students or amongst them.

The simulation of ICMLS version 1.0 developed next was packaged in measurable learning videos in order to gradually measure the interaction between the results of the observation of the practice process through the engineering of the learning environment in a usually large and wide laboratory. There was also a large set of instructional design theories that prescribe how these types of environments should be designed [28].

\section{$5 \quad$ Conclusion and Recommendations}

\subsection{Conclusion}

ICMLS is a digital learning prototype developed in the form of a mobile laboratory that can be used to improve competence in practical activities of Computer and Network Engineering Study Programs students. The use of this tool is easier, more 
concise and fun with a variety of futuristic and innovative features to increase student learning motivation. Furthermore, schools are no longer burdened with having to add space to a laboratory because ICML is portable, light and easy to carry. The result of the analysis conducted on 8 Vocational Schools showed a very significant increase in the average competency skill of students and all the score achievements.

\subsection{Recommendations}

The application of ICMLS provided several advantages and competencies for vocational students of Computer and Network Engineering Program. Therefore, it is recommended that the next product should focus on software, networking, and other features in order to fulfill the instructional design model [29]. This should be further implemented until the product can be easily and cheaply fabricated with the help of industrial partners.

\section{Acknowledgement}

This research was granted financial support from Research Grand for Universitas Pendidikan Indonesia, on 2018 and PT. INTI as Industry Support.

\section{References}

[1] Wang, J. (2006). Managing national reputation and international relations in the global era: Public diplomacy revisited. Public Relations Review. Volume 32, Issue 2, June 2006, Pages 91-96. https://doi.org/10.1016/j.pubrev.2005.12.001

[2] Guo, L., Fu, Y., Yin, X., Yuan, M., Zhang, F., \& Gao, J. (2013). Application of Mobile Learning System in Operating System Course, 2013(May), 157-160. https://doi.org/10.4236/cn.2013.52017

[3] Ngah, N., Ismail, Z., Tasir, Z., Nihra, M., \& Mohamad, H. (2017). Student's Higher Order Thinking Skills and Its Relationship to Problem Posing Ability, (April). https://doi.org/10.1166/asl.2017.7589

[4] Morrar, R., Arman, H., Mousa, S., \& Schwab, K. (2017). The Fourth Industrial Revolution (Industry 4.0): A Social Innovation Perspective, 7(11), 12-21. https://doi.org/10. 22215/timreview/1117

[5] West, R. E., Thomas, R. A., Bodily, R., Wright, C., \& Borup, J. (2017). An analysis of instructional design and technology departments. Educational Technology Research and Development, 65(4), 869-888. https://doi.org/10.1007/s11423-016-9490-1

[6] Eichmann, Beate, et al. 2019. Computers \& Education The Role of Planning in Complex Problem Solving. 128(August 2018): 1-12.

[7] Van der Meij, H., van der Meij, J., \& Harmsen, R. (2015). Animated pedagogical agents effects on enhancing student motivation and learning in a science inquiry learning environment. Educational Technology Research and Development, 63(3), 381403.https://doi.org/10.1007/s11423-015-9378-5

[8] My, R., \& Liu, J. (2013). Design and Implementation of Mobile Services Evaluation System, 2013(September), 348-354. 
[9] Evans, S. K., Pearce, K. E., Vitak, J., \& Treem, J. W. (2017). Explicating Affordances: A Conceptual Framework for Understanding Affordances in Communication Research. Journal of Computer-Mediated Communication, 22(1), 35-52. https://doi.org/10.1111/ jcc4.12180. https://doi.org/10.1111/jcc4.12180

[10] He, L., \& He, J. (2015). The Revolution of Communication Media and Its Impact on Education. Open Journal of Social Science, (August), 123-127. https://doi.org/10. 4236/jss.2015.38014

[11] Gibbs, J. L., Rozaidi, N. A., \& Eisenberg, J. (2013). Overcoming the"Ideology of Openness ": Probing the Affordances of Social Media for Organizational Knowledge Sharing, 19, 102-120. https://doi.org/10.1111/jcc4.12034

[12] Baiyere, A., \& Salmela, H. (2015). Review: Disruptive Innovation \& Information Technology - Charting a path Review: Disruptive Innovation \& Information Technology Charting a path, (December 2013).

[13] Darmawan, D., Kartawinata, H., Astorina, W. (2018). Development of Web-Based Electronic Learning System (WELS) in Improving the Effectiveness of the Study at Vocational High School "Dharma Nusantara. Journal of Computer Science. 2018, 14 (4): 562.573. https://doi.org/10.3844/jcssp.2018.562.573

[14] Lee, J., Lim, C., \& Kim, H. (2017). Development of an instructional design model for flipped learning in higher education. Educational Technology Research and Development, 65(2), 427-453. https://doi.org/10.1007/s11423-016-9502-1

[15] Hanus, M. D., \& Fox, J. (2018). Computers \& Education Corrigendum to Assessing the Effects of Gamification in the Classroom: A Longitudinal Study on Intrinsic Motivation, Social Comparison, Satisfaction, Effort, and Academic Performance Computers \& Education 80 (2015) Pages 152-161. Computers \& Education, 127, 298. https://doi.org/10.1016/j.compedu.2018.09.019.

[16] House, T. C. (2013). A Secure Approach to Educating a Mobile World-Class Military A Mobile Secure Concept for Accessing the Classroom from Around the World, 2013(September), 473-477. https://doi.org/10.4236/cn.2013.53b2087

[17] Fayyoumi, A., Mohammad, H., \& Faris, H. (2013). Mobile Based Learning and Examination: Students and Instructors Perceptions from Different Arab Countries, 2013(December), 662-669. https://doi.org/10.4236/jsea.2013.612079

[18] Gall, M. D. (1996). Educational Research: An Introduction, 6th Edition. New York: Longman.

[19] Noroozi, O., Busstra, M. C., Mulder, M., \& Biemans, H. J. A. (2012). Online discussion compensates for suboptimal timing of supportive information presented in a digitally supported learning environment, 193-221. https://doi.org/10.1007/s11423-011-9217-2.

[20] Fabian, K., Topping, K. J., \& Barron, I. G. (2018). Using mobile technologies for mathematics: effects on student attitudes and achievement. Educational Technology Research and Development, 66(5), 1119-1139. https://doi.org/10.1007/s11423-018-9580-3

[21] Kahn, P., Everington, L., Kelm, K., Reid, I., \& Watkins, F. (2017). Understanding student engagement in online learning environments: the role of reflexivity. Educational Technology Research and Development, 65(1), 203-218. https://doi.org/10.1007/ s11423-016-9484-Z

[22] Ossiannilsson, E. (2017). Blended Learning State of the Nation.Oslo: International Council for Open and Distance Education -ICDE.

[23] Ruggiero, Dana, and Jeffrey D Boehm. (2018). Computers \& Education Retraction Notice to " Project-Based Learning in a Virtual Internship Programme: A Study of the Interrelated Roles between Intern, Mentor and Client. [10. 1016 / j. Compedu. 2017. 03. 011].” 
Paper-Development of ICMLS Version 2 (Integrated Communication and Mobile Laboratory) ...

Computers \& Education 127: 299. https://doi.org/10.1016/j.compedu. 2018.09.018

[24] Hilton, J. (2016). Open educational resources and college textbook choices: a review of research on efficacy and perceptions. Educational Technology Research and Development, 64(4), 573-590. https://doi.org/10.1007/s11423-016-9434-9

[25] Ioan, Catalin, Ana-maria Cazan, Radu Constantin, and Lavinia Dovleac. 2019. Computers \& Education A Study on Academic Staff of Personality and Technology Acceptance: The Case of Communication and Collaboration Applications. 128(March 2018): 113-31. https://doi.org/10.1016/j.compedu.2018.09.010

[26] Jere-Folotiya, J., Chansa-Kabali, T., Munachaka, J. C., Sampa, F., Yalukanda, C., Westerholm, J.,Lyytinen, H. (2014). The effect of using a mobile literacy game to improve literacy levels of grade one students in Zambian schools. Educational Technology Research and Development, 62(4), 417-436. https://doi.org/10.1007/s11423-014-9342-9

[27] Powell, R. G., \& Powell, D. L. (2017). Classroom Communication and Diversity.NewJersey: Prentice Hall. Company.

[28] De Jong, T., Weinberger, A., Girault, I., Kluge, A., Lazonder, A. W., Pedaste, M., Zacharia, Z. C. (2012). Using scenarios to design complex technology-enhanced learning environments. Educational Technology Research and Development, 60(5), 883901.https://doi.org/10.1007/s11423-012-9258-1

[29] Filius, Renée M, et al. (2018). Computers \& Education Strengthening Dialogic Peer Feedback Aiming for Deep Learning in SPOCs. Computers \& Education 125(June): 86100. https://doi.org/10.1016/j.compedu.2018.06.004

\section{Author}

Deni Darmawan currently works at the Department of Curriculum Studies and Educational Technology, and Communication Science of Universitas Pendidikan Indonesia. Their current project is 'ministry of education in Indonesia'. Email: deni_darmawan@upi.edu

Article submitted 2019-12-04. Resubmitted 2020-01-27. Final acceptance 2020-02-12. Final version published as submitted by the authors. 